\title{
Rapid Detection and Differentiation of Three Cucurbit-infecting Poleroviruses by Multiplex RT-PCR
}

\author{
Qiaoxia Shang \\ Department of Plant Science and Technology, Beijing University of Agriculture \\ No.7 Beinong Road, Beijing 102206, China \\ $\&$
}

State Key Laboratory for Agro-biotechnology and Department of Plant Pathology

China Agricultural University. No.2 Yuanmingyuan West Road, Beijing 100193, China

E-mail: shangqiaoxia@yahoo.com.cn

Haiying Xiang (Co-first author)

State Key Laboratory for Agro-biotechnology and Department of Plant Pathology

China Agricultural University

No.2 Yuanmingyuan West Road, Beijing 100193, China

E-mail: xhy236@yahoo.com.cn

Dawei Li

State Key Laboratory for Agro-biotechnology, China Agricultural University

No.2 Yuanmingyuan West Road, Beijing 100193, China

E-mail: lidw@cau.edu.cn

Jialin Yu

State Key Laboratory for Agro-biotechnology, China Agricultural University

No.2 Yuanmingyuan West Road, Beijing 100193, China

E-mail: bnyvv@public.bta.net.cn

Chenggui Han (Corresponding author)

State Key Laboratory for Agro-biotechnology and Department of Plant Pathology

China Agricultural University

No.2 Yuanmingyuan West Road, Beijing 100193, China

Tel: 86-10-6273-3336 E-mail: hanchenggui@cau.edu.cn

Received: October 31, $2011 \quad$ Accepted: November 21, $2011 \quad$ Online Published: February 2, 2012

doi:10.5539/jas.v4n4p209

URL: http://dx.doi.org/10.5539/jas.v4n4p209

The research is supported by the National Natural Science Foundation of China (No. 31000840 and No.31071663), the Natural Science Foundation of Beijing (No.6082006) and the Science and Technology Nova Program of Beijing (No.2007B032).

\footnotetext{
Abstract

A multiplex reverse transcription polymerase chain reaction (mRT-PCR) method was developed and optimized for the simultaneous detection and differentiation of three poleroviruses infecting cucurbits. Cucurbit
} 
aphid-borne yellows virus (CABYV), Melon aphid-borne yellows virus (MABYV) and Suakwa aphid-borne yellows virus (SABYV) could be differentiated simultaneously using four optimized specific oligonucleotide primers, including one universal primer for detecting poleroviruses and three virus-specific primers. Amplification of three target viruses was also optimized by increasing the PCR annealing temperatures. The mRT-PCR products consisted of fragments of 700 base pairs (bp) for CABYV, $450 \mathrm{bp}$ for MABYV and $950 \mathrm{bp}$ for SABYV. Detection limits of the RNA quantity for mRT-PCR were $1 \mathrm{pg}$ for CABYV, $0.1 \mathrm{pg}$ for MABYV and $1 \mathrm{pg}$ for SABYV. No specific products could be amplified from RNA of other non-target poleroviruses. The mRT-PCR was found to be a specific, sensitive and cost-effective method for detecting multiple poleroviruses in cucurbits.

Keywords: Cucurbit poleroviruses, Cucurbit aphid-borne yellows virus, Melon aphid-borne yellows virus, Suakwa aphid-borne yellows virus, Multiplex RT-PCR

\section{Introduction}

Cucurbits are cultivated widely in China, but viral diseases can lead to lethal syndromes, regular epidemics and considerable economic losses. Cucurbit aphid-borne yellows virus (CABYV) is the first reported polerovirus infecting cultivated cucurbits naturally and significantly reduces yield in France (Abou-Jawdah et al., 1997; Lecoq et al., 1992). Yield losses of up to $40 \%$ have been reported in melon plants, and although fruit shape and quality are not adversely impacted, infected plants characteristically produce fewer fruits per plant (Lecoq et al., 1992). Subsequently, CABYV has been found in Italy, Lebanon, Spain, Iran, Turkey, Tunisia and the USA (Abou-Jawdah et al., 1997; Bananej et al., 2006; D`Arcy and Domer, 2005; Juarez, 2004; Lecoq et al., 1992; Lemaire et al., 1993; Mnari-Hattab, 2005; Tomassoli and Meneghini, 2007; Yardımcı and O"zgo"nen, 2007).

In 2006, CABYV was first detected in mainland China from nine cucurbit crops showing yellowing symptoms (Xiang et al., 2008b). Later, two new poleroviruses infecting cucurbits in China, Melon aphid-borne yellows virus (MABYV) and Suakwa aphid-borne yellows virus (SABYV), were found in our study. MABYV is accepted as one of the 13 formally described virus species, and SABYV remains a tentative designation within the Polerovirus genus by the International Committee on Taxonomy of Viruses (Knierim et al., 2010; Shang et al., 2009; Xiang et al., 2008a).

Poleroviruses are plant viruses that contain a small, single molecule of linear, positive-sense ssRNA (D`Arcy and Domer, 2005; Prufer et al., 1995). The virus particles are approximately 25 to $30 \mathrm{~nm}$ in diameter, are isometric and hexagonal in outline, and have no envelope (D`Arcy and Domer, 2005). These plant viruses are phloem restricted and are not uniformly distributed in hosts (Hoffmann et. al., 2001). The routine serological detection method using polyclonal antibodies lacks the sensitivity necessary to detect poleroviruses, given that the virus occurs at very low or variable concentrations. Furthermore, current serological assays cannot differentiate the various polerovirus species that infect cucurbits, due to cross reactions (D'Arcy et al., 1989; Mnari-Hattab et al., 2009; Robertson et al., 1991). However, RT-PCR with specific primers can distinguish among these virus species (Hauser et al., 2000; Knierim et al., 2010; Lemaire et al., 1995; Mnari-Hattab et al., 2009; Shang et al., 2009; Xiang et al., 2008a; Xiang et al., 2008b).

The polerovirus genome contains six open reading frames (ORFs), has a VPg linked to the 5 ' end of the genomic RNA and lacks a poly(A) tract or a tRNA-like structure on the $3^{\prime}$ end (Fig. 1) (D'Arcy and Domer, 2005). Poleroviruses possess an ORF0 in the $5^{\prime}$ end and a non-coding region of about 200 nucleotides (nt) between ORF2 and ORF3 (D'Arcy and Domer, 2005). RT-PCR with universal primers allows for the amplification of a $1.4 \mathrm{~kb}$ band for poleroviruses (Xiang et al., 2008a; Xiang et al., 2008b). Other primers have been used to separately detect CABYV, MABYV and SABYV, in order to describe the geographical distribution and molecular diversity of these poleroviruses in China. However, these methods only recognize one virus at a time (Shang et al., 2009; Xiang et al., 2008a). The detection of several different viruses from large numbers of cucurbit samples by running multiple simplex PCRs per sample is unnecessarily costly and time-consuming (Knierim et al., 2010; Shang et al., 2009; Xiang et al., 2008a). Multiplex RT-PCR is a popular technique that offers fast, reliable and cost-effective detection of multiple viruses simultaneously (Deb and Anderson, 2008; Viganó and Stevens, 2007; Wei et al., 2009). Here, we report a specific and sensitive multiplex RT-PCR method that can detect and differentiate three poleroviruses, CABYV, MABYV and SABYV, infecting cucurbit crops.

\section{Materials and Methods}

\subsection{Plant material and Recombinant Plasmids}

Cucurbit leaf tissues infected with individual known poleroviruses, CABYV, MABYV and SABYV, were used to standardize the multiplex RT-PCR. Each of these three viruses infecting cucurbits was identified by RT-PCR 
and sequenced in our previous research (Shang et al., 2009). Additional cucurbit samples from different fields in China showing leaf-yellowing symptoms were collected for testing.

RT-PCR products amplified with primers for polerovirus detection (PococpR/ PoconF) were purified, using a PCR DNA Purification Kit (Axygen) according to the manufacturer's instructions, and inserted into the pMD19-T vector (TaKaRa). Plasmids pCaCAI-169, pCaMA5-85 and pTSAB-1, harboring the expected size inserts for each PCR product from viruses CABYV, MABYV and SABYV, respectively, were constructed and used to study multiplex PCR. Plasmids containing partial sequence cDNA clones of Turnip yellows virus (TuYV) and Sugarcane yellow leaf virus (ScYLV), two other poleroviruses constructed in our previous research, were used to test specificity of the multiplex PCR.

\subsection{RNA Extraction and RT-PCR Detection}

Total RNA from $0.3 \mathrm{~g}$ of leaf tissue from infected plants was prepared by SDS-phenol/chloroform extraction and eluted in a final volume of $10 \mu \mathrm{l}$ of diethylpyrocarbonate-treated (DEPC) water and stored at $-20^{\circ} \mathrm{C}$ for the following protocols (Han et al., 2000).

Two-step RT-PCR detection for poleroviruses was performed as described earlier (Shang et al., 2009; Xiang et al., 2008a). Amplified products ( $5 \mu$ each) were electrophoresed in $1 \%$ agarose gels and stained with ethidium bromide to confirm the expected size of the fragments.

\subsection{Primer Selection and Optimization of Annealing Temperatures}

The multiplex RT-PCR assay was designed to be carried out using a mixture of the universal polerovirus primer PococpR and primers specific for different viruses.

Three specific sense primers, CA3414F, MA3566F and SA3133F, had been used to detect CABYV, MABYV and SABYV separately in simplex PCR (Shang et al., 2009; Xiang et al., 2008a). However, a multiplex PCR containing each of the four primers described above could not differentiate the three viruses, even under varied PCR conditions. Under most conditions, the cDNA of MABYV could not be amplified in multiplex PCR. Accordingly, we designed other primers for the detection of MABYV based on its RNA sequence (GenBank Accession No. NC010809). We gave consideration to the size of the PCR product and to the interaction between primers, which can affect amplification efficiency. The sequences of the designed primers used in this study are listed in Table 1.

The optimization of annealing temperatures was based on $50^{\circ} \mathrm{C}$ in initial protocols. Gradient PCR was performed using different temperatures that were set randomly from $45^{\circ} \mathrm{C}$ to $58^{\circ} \mathrm{C}$ by the PCR machine.

\subsection{Cloning and Sequencing}

Purified PCR products, amplified with primers PoT7conF and PoE5cocpR from clones pCaCAI-169, pCaMA5-85 and pTSAB-1, were inserted into pMD19-T and then transformed into competent cells of Escherichia coli $\mathrm{DH} 5 \alpha$. The sequences of the primers designed for construction of recombinant clones are listed in Table 2. Recombinant clones pMD-CAT7-9, pMD-MAT7-19 and pMD-SAT7-45, containing about $1400 \mathrm{nt}$ of the cDNA fragments of CABYV, MABYV and SABYV, were constructed and included T7 polymerase and EcoRV restriction enzyme sites.

All clones were selected and identified by using colony PCR, and sequenced with M13-47 forward and M13-48 reverse primers by the dideoxynucleotide chain termination method using an automated sequencer (ABI Prism ${ }^{\mathrm{TM}}$ 3730, Applied Biosystems, USA) and the Big-Dye ${ }^{\mathrm{TM}}$ Terminator Cycle Sequencing Ready Reaction Kit.

\subsection{In vitro RNA Transcription and Quantification}

Plasmids pMD-CAT7-9, pMD-MAT7-19 and pMD-SAT7-45 were linearized by EcoRV restriction digestion and transcribed in vitro by T7 RNA polymerase. Reaction mixtures contained the following in a final volume of 50 $\mu \mathrm{l}: 1 \mu \mathrm{g}$ linear plasmid DNA, $2 \mu \mathrm{l} 20 \mathrm{U} / \mu \mathrm{l} \mathrm{T7}$ RNA polymerase and $10 \mu \mathrm{l}$ X T7 polymerase reaction buffer, $5 \mu \mathrm{l}$ $100 \mathrm{mM}$ DTT, $1 \mu \mathrm{l}$ RNasin, $2.5 \mu \mathrm{l} / \mathrm{each} 10 \mathrm{mM}$ ATP/GTP/CTG/UTP. The reaction mixtures were incubated at $37^{\circ} \mathrm{C}$ for $90 \mathrm{~min}$, and the RNA polymerization reaction was terminated by the addition of $1 \mu \mathrm{l}$ Rase-free DNaseI, followed by incubation at $37^{\circ} \mathrm{C}$ for $30 \mathrm{~min}$ according to the manufacturer's protocol (Promega, USA). Confirmation that the RNA bands represented full-length transcripts was conducted by electrophoresis in a $1 \%$ agarose gel, and the product RNA molecules were quantified and tested by Nano analysis.

\subsection{Sensitivity of Multiplex PCR}

The sensitivity was considered as the lowest concentration of viral RNA giving a strong positive signal in mRT-PCR. To determine this threshold, ten-fold serially diluted RNA templates of three viruses were tested 
using a one-step RT-PCR kit (Qiagen, USA). Polerovirus RNA samples, ranging in quantity from $1 \mathrm{fg}$ to $10 \mathrm{ng}$, were prepared in $5 \mu \mathrm{l}$ of RNA extracted from healthy cucurbit leaf tissue and the assay was carried out as described above.

\section{Results}

\subsection{Primer Selection and Optimization of Annealing Temperatures}

Published universal polerovirus primer PococpR and species-specific primers CA3414F and SA3133F were used in our study (Shang et al., 2009; Xiang et al., 2008a). A newly designed primer MA3639F was included, to allow for mRT-PCR. We developed an mRT-PCR method using the four primers listed above that were capable of differentiating CABYV, MABYV and SABYV in infected plant tissue. Annealing temperatures between $45^{\circ} \mathrm{C}$ and $58^{\circ} \mathrm{C}$ were tested in order to optimize amplification by the Gradient PCR machine based on $50^{\circ} \mathrm{C}$ in our initial protocols (Wei et al., 2009). The optimal annealing temperature for mRT-PCR was determined to be $51^{\circ} \mathrm{C}$. The mRT-PCR products were $700 \mathrm{bp}$ for CABYV, $450 \mathrm{bp}$ for MABYV and $950 \mathrm{bp}$ for SABYV. A negative control containing RNA from an uninfected leaf gave no signal (Fig. 2).

\subsection{Sensitivity and Specificity of Multiplex PCR}

The detection limit of the multiplex PCR was determined by testing ten-fold serial dilutions of the individual transcribed RNA from CABYV, MABYV and SABYV. The quantities of in vitro-transcribed RNA with known sequence were tested and serially diluted with healthy plant RNA. The specific PCR products created using diluted individual transcribed RNA target were detected after agarose gel electrophoresis by ethidium bromide staining (Fig. 3). Detection limits of the RNA quantity for mRT-PCR were $1 \mathrm{pg}$ for CABYV, $0.1 \mathrm{pg}$ for MABYV and $1 \mathrm{pg}$ for SABYV. Plasmids containing cDNA sequences from two other poleroviruses, TuYV and ScYLV, were used to test the specificity of the multiplex PCR, and gave no signal (Fig. 2).

\subsection{Detection of the Three Poleroviruses in Field Samples}

Cucurbit leaf tissue samples collected from different fields in China were used to test and standardize the mRT-PCR (Fig. 4). Samples of cushaw and squash from Fujian, cucumbers from Beijing, Suakwa vegetable sponge, and squash and cushaw from Jiangxi in China were tested. The positive control containing RNA of CABYV, MABYV and SABYV could produce three distinct fragments, $700 \mathrm{bp}, 450 \mathrm{bp}$ and $950 \mathrm{bp}$, respectively. All of the negative controls, including healthy plant samples, gave no signal as expected. In all single infections and combinations of simulated double infections, the viruses were detected and differentiated by the multiplex PCR in a single reaction using four primers together. The results were confirmed by monospecific RT-PCR. Because of the high sensitivity and specificity of the mRT-PCR method, it is easy to differentiate poleroviruses in cucurbit samples infected by CABYV, MABYV and/or SABYV.

\section{Discussion}

There have been considerable advances in the field of viral diagnosis, which have been brought about by rapidly advancing PCR methods that enable the diagnosis of specific viral infections. Furthermore, multiplex RT-PCR for the detection of different viruses simultaneously is popular because it provides fast, reliable and cost-effective results (Deb and Anderson, 2008; Viganó and Stevens, 2007; Wei et al., 2009).

The mRT-PCR method developed here was able to detect and differentiate simultaneously CABYV, MABYV and SABYV in one single reaction. Poleroviruses have become very important viruses infecting cucurbit crops in the world. In mainland China, CABYV is prevalent and widely occurring on nine cucurbit crops at least in 25 different provinces, while MABYV was found in Beijing, Inner Mongilia, Anhui, Jiangxi and Hainan provinces. To date, SABYV has been detected only in the southern parts of China, including the Guangxi, Guangdong and Fujian provinces (Knierim et al., 2010; Shang et al., 2009; Xiang et al., 2008b). In the past, the detection of these poleroviruses required separate, simplex PCR. Therefore, an mRT-PCR method which can rapidly identify poleroviruses will be important and helpful in studying the distribution and control of cucurbit poleroviral disease. The mRT-PCR is sensitive, specific, cost effective and useful in detection, and has the added benefits of saving time and using fewer reagents compared with simplex RT-PCR (Deb and Anderson, 2008). The application of this mRT-PCR-based assay to field samples resulted in the direct detection of RNA from CABYV, MABYV and/or SABYV infecting cucurbits.

The universal set of primers for poleroviruses were able to amplify a $1.4 \mathrm{~kb}$ DNA band for any of the poleroviruses, and three specific sense primers, CA3414F, MA3566F and SA3133F, were used to detect CABYV, MABYV and SABYV separately in simplex PCR as we reported (Knierim et al., 2010; Shang et al., 2009; Xiang et al., 2008b). It has been reported that amplification efficiency is inversely correlated with the amplicon size (Wei et al., 2009); shorter products could be preferentially amplified compared to larger products, although that 
is not always the case. In our study, the shortest product of the cDNA of MABYV could not be amplified in multiplex PCR while other longer products from CABYV and SABYV could be amplified. So, newly designed primers were tested and then one of those primers, MA3639F, was selected to be used in mRT-PCR. Annealing temperature is an important factor for PCR specificity and amplification efficiency (Ma and Michailides, 2007; Wei et al., 2009). Therefore, the annealing temperature was optimized. The results indicate that the primers were correctly designed to avoid possible primer-dimers, and the mRT-PCR was specific and sensitive for detecting different targets in a single reaction. In our study, the newly developed multiplex RT-PCR could detect and simultaneously differentiate CABYV, MABYV and SABYV in one reaction using primers PococpR, CA3414F, MA3639F and SA3133F, which can also be used in monospecific RT-PCR.

The approach developed in this study provides a simple and convenient way to develop multiplex assays based on published primers, supplemented with newly designed primers where necessary. This specific and sensitive method for detecting multiple poleroviruses in cucurbits could be used for large-scale sampling efforts to study the distribution of poleroviruses in China as well as other areas in the world. This detection technique could facilitate research on cucurbit-infecting polerovirus epidemiology, outbreak monitoring and investigations of interactions among viruses, hosts and vectors.

\section{Acknowledgements}

We thank Matthew Bakker (Department of Plant Pathology, University of Minnesota, USA) for help proofreading the manuscript.

\section{References}

Abou-Jawdah, Y. S. H. \& Fayyad, A. (1997). First report of cucurbit aphid-borne yellows luteovirus in Lebanon. Plant Disease, 81, 1. http://dx.doi.org/10.1094/PDIS.1997.81.11.1331D

Bananej, K., Desbiez, C., Wipf-Scheibel, C., Vahdat, I., Kheyr-Pour, A., Ahoonmanesh, A. \& Lecoq, H. (2006). First report of Cucurbit aphid-borne yellows virus in Iran causing yellows on four cucurbit crops. Plant Disease, 90, 526-526. http://dx.doi.org/10.1094/PD-90-0526A

D'Arcy, C.J., Torrance, L. \& Martin, R.R. (1989). Discrimination among luteoviruses and their strains by monoclonal antibodies and identification of common epitopes. Phytopathololgy, 79, 869-873. http://dx.doi.org/10.1094/Phyto-79-869

D`Arcy, C.J. \& Domer, L. (2005). Luteoviridae. In F. CM, M. MA, Maniloff J, D. U \& B. LA (Eds.), Virus Taxonomy, VIIIth Report of the ICTV (pp. 891-900). London: Elsevier/Academic Press.

Deb, M. \& Anderson, J.M. (2008). Development of a multiplexed PCR detection method for Barley and Cereal yellow dwarf viruses, Wheat spindle streak virus, Wheat streak mosaic virus and Soil-borne wheat mosaic virus. Journal of Virology Methods, 148, 17-24. http://dx.doi.org/10.1016/j.jviromet.2007.10.015

Han, C., Li, D., Xing, Y. \& Yu, J. (2000). Wheat yellow mosaic virus widely occurring in wheat in China. Plant Disease, 84, 627-630. http://dx.doi.org/10.1094/PDIS.2000.84.6.627

Hauser, S., Stevens, M., Mougel, C., Smith, H.G., Fritsch, C., Herrbach, E. \& Lemaire, O. (2000). Biological, serological, and molecular variability suggest three distinct polerovirus species infecting beet or rape. Phytopathology, 90, 460-466. http://dx.doi.org/10.1094/PHYTO.2000.90.5.460

Juarez, M. (2004). First report of Cucurbit aphid-borne yellows virus in Spain. Plant Disease, 88, 907. http://dx.doi.org/10.1094/PDIS.2004.88.8.907A

Knierim, D., Deng, T., Tsai, W.S., Green, S.K. \& Kenyon, L. (2010). Molecular identification of three distinct Polerovirus species and a recombinant Cucurbit aphid-borne yellows virus strain infecting cucurbit crops in Taiwan. Plant Pathology, 59, 11. http://dx.doi.org/10.1111/j.1365-3059.2010.02327.x

Lecoq, H., Bourdin, D., Wipe-scheibel, C., Bon, M. \& Lot, H. (1992). A new yellowing disease of cucurbits caused by a luteovirus, Cucurbit Aphid-Borne Yellows virus. Plant Pathology, 41, 749-761. http://dx.doi.org/10.1111/j.1365-3059.1992.tb02559.x

Lemaire, O., Gubler, W.D., Valencia, J., Lecoq, H. \& Falk, B.W. (1993). First report of Cucurbit aphid-borne yellows virus in the United States. Plant Disease, 77, 1169. http://dx.doi.org/10.1094/PD-77-1169B

Lemaire, O., Herrbach, E., Stevens, M., Bouchery, Y. \& Smith, H.G. (1995). Detection of sugar beet-infecting beet mild yellowing luteovirus isolates with a specific RNA probe. Phytopathology, 85, 1513-1518. http://dx.doi.org/10.1094/Phyto-85-1513

Ma, Z. \& Michailides, T.J. (2007). Approaches for eliminating PCR inhibitors and designing PCR primers for the 
detection of phytopathogenic fungi. Crop Protection, 26, 145-161. http://dx.doi.org/10.1016/j.cropro.2006.04.014

Mnari-Hattab, M. (2005). First report of Cucurbit aphid-borne yellows virus in Tunisia causing yellows on five cucurbitaceous species. Plant Disease, 89, 776. http://dx.doi.org/10.1094/PD-89-0776B

Mnari-Hattab, M., Gauthier, N. \& Zouba, A. (2009). Biological and Molecular Characterization of the Cucurbit aphid-borne yellows virus Affecting Cucurbits in Tunisia. Plant Disease, 93, 1065-1072. http://dx.doi.org/10.1094/PDIS-93-10-1065

Prufer, D., Wipf-Scheibel, C., Richards, K., Guilley, H., Lecoq, H. \& Jonard, G. (1995). Synthesis of a full-length infectious cDNA clone of cucurbit aphid-borne yellows virus and its use in gene exchange experiments with structural proteins from other luteoviruses. Virology, 214, 150-158. http://dx.doi.org/10.1006/viro.1995.9945

Robertson, N.L., French, R. \& Gray, S.M. (1991). Use of group-specific primers and the polymerase chain reaction for the detection and identification of luteoviruses. Journal of General Virololgy, 72, 1473-1477. http://dx.doi.org/10.1099/0022-1317-72-6-1473

Shang, Q., Xiang, H., Han, C., Li, D. \& Yu, J. (2009). Distribution and molecular diversity of three cucurbit-infecting poleroviruses in China. Virus Research, 145, 341-346. http://dx.doi.org/10.1016/j.virusres.2009.07.017

Tomassoli, L. \& Meneghini, M. (2007). First report of Cucurbit aphid-borne yellows virus in Italy. Plant Pathology, 56, 720. http://dx.doi.org/10.1111/j.1365-3059.2007.01583.x

Viganó, F. \& Stevens, M. (2007). Development of a multiplex immunocapture-RT-PCR for simultaneous detection of BMYV and BChV in plants and single aphids. Journal of Virological Methods, 146, 196-201. http://dx.doi.org/10.1016/j.jviromet.2007.06.018

Wei, T., Lu, G. \& Clover, G. (2009). A multiplex RT - PCR for the detection of Potato yellow vein virus, Tobacco rattle virus and Tomato infectious chlorosis virus in potato with a plant internal amplification control. Plant Pathology, 58, 203-209. http://dx.doi.org/10.1111/j.1365-3059.2008.01979.x

Xiang, H., Shang, Q., Han, C., Li, D. \& Yu, J. (2008a). Complete sequence analysis reveals two distinct poleroviruses infecting cucurbits in China. Archives of Virology, 153, 1155-1160. http://dx.doi.org/10.1007/s00705-008-0083-0

Xiang, H., Shang, Q., Han, C., Li, D. \& Yu, J. (2008b). First report on the occurrence of Cucurbit aphid-borne yellows virus on nine cucurbitaceous species in China. Plant Pathology, 57, 390.

Yardımcı, N. \& O"zgo"nen, H. (2007). First report of Cucurbit aphid-borne yellows virus in Turkey. Australasian Plant Disease Notes, 2, 59.

Table 1. List of primers used for developing multiplex RT-PCR

\begin{tabular}{|l|l|l|}
\hline Primer & Sequence (5' to 3') & Product (bp) \\
\hline MA3817F & AGTATAAAATCTCAATGGTCAAGT & 283 \\
\hline MA3340F & AGCCGGAAATACGTTGTTGCAATTGC & 760 \\
\hline MA3420F & ATTCACATCGGGCTTCCTGG & 680 \\
\hline MA3603F & GTGGTCCAAACCACTGGCCA & 497 \\
\hline MA3639F & CGACGACGACGAAATCCAA & 461 \\
\hline CA3488F & GCACACGTGCGTTCAATTGTTAATG & 612 \\
\hline
\end{tabular}


Table 2. Primers and designing rules used for constructing recombinant clones

\begin{tabular}{|l|l|l|}
\hline Primer & Sequence (5' to 3') & Designing rule \\
\hline PoT7conF & $\begin{array}{l}\text { GTAATACGACTCACTATAGTG } \\
\text { YTCYGGTTTTGACTGG }\end{array}$ & $\begin{array}{l}\text { 19nt added to the 5'-end of primer PoconF, including } \\
\text { promoter sequence of phage T7 polymerase (shaded) } \\
\text { and additional G for enhancing transcription } \\
\text { (underlined). }\end{array}$ \\
\hline PoE5cocpR & $\begin{array}{l}\text { GATATCGGATCCCGTCTACCT } \\
\text { ATTTSGGRTTN }\end{array}$ & $\begin{array}{l}\text { 12nt added to the 5'-end of primer PococpR, including } \\
\text { restriction enzyme cutting site of EcoR V and } \\
\text { BamH I (shaded). }\end{array}$ \\
\hline sqxT7 & GTAATACGACTCACTATAG & $\begin{array}{l}\text { Primer with promoter sequence of phage T7 polymerase } \\
\text { (shaded) and additional G (underlined) designed for the } \\
\text { detection of recombinant clones. }\end{array}$ \\
\hline
\end{tabular}

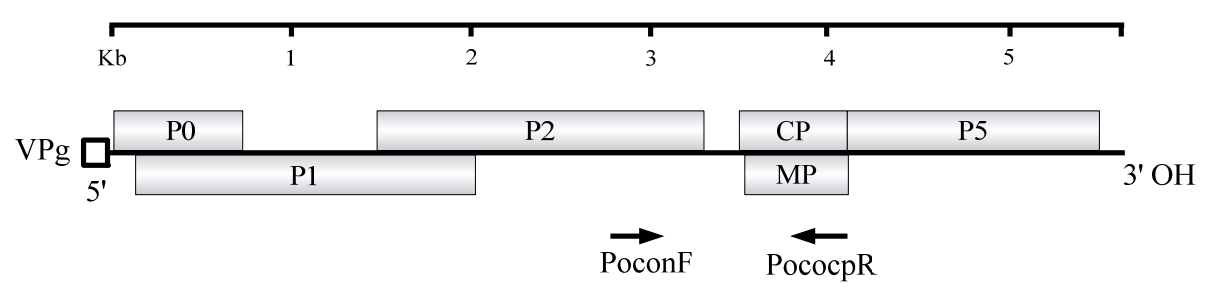

Figure 1. Diagram of the genome organization of poleroviruses

Solid lines represent RNA; boxes represent ORFs; square represents VPg. Arrowheads represent the positions of the universal primers for the detection of poleroviruses.

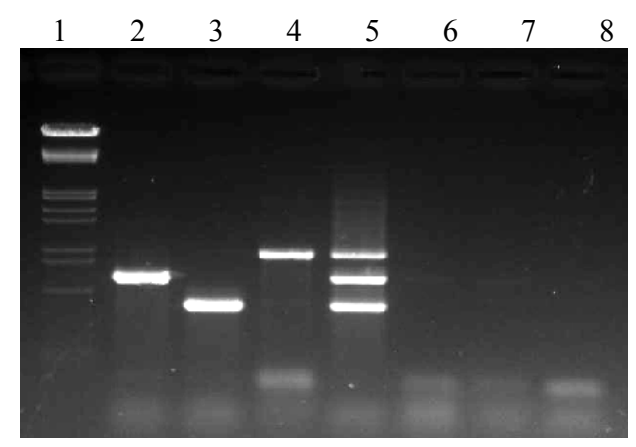

Figure 2. Agarose gel electrophoresis of multiplex RT-PCR products of different poleroviruses infecting cucurbits Lane 1, DNA size marker, $\lambda$ DNA digested by EcoRI and HindIII; Lane 2, CABYV; Lane 3, MABYV; Lane 4, SABYV; Lane 5, CABYV, MABYV and SABYV; Lane 6, TuYV; Lane 7, ScYLV; Lane 8, no template. 


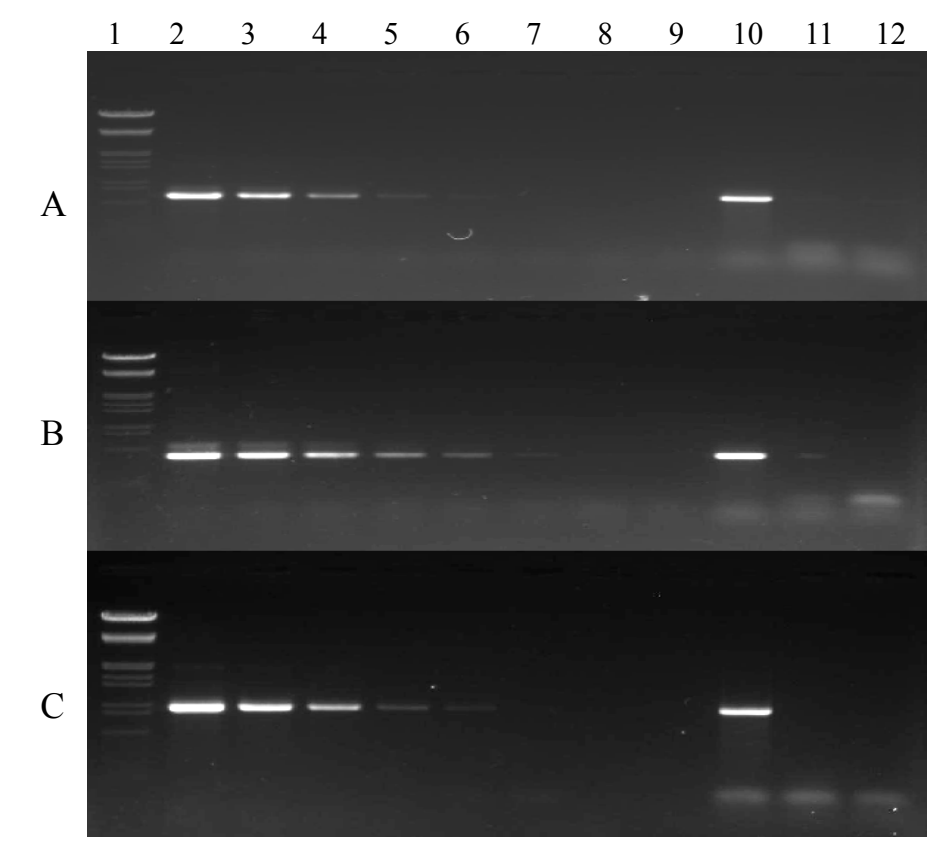

Figure 3. Evaluation of the detection limit of multiplex RT-PCR using ten-fold serial dilutions of individually transcribed RNA from CABYV, MABYV and SABYV

A for CABYV; B for MABYV; C for SABYV.

Lane 1, DNA size marker, $\lambda$ DNA digested by EcoRI and HindIII; Lanes 2-9, $10 \mathrm{ng}, 1 \mathrm{ng}, 0.1 \mathrm{ng}, 10 \mathrm{pg}, 1 \mathrm{pg}$, $0.1 \mathrm{pg}, 10 \mathrm{fg}$ and $1 \mathrm{fg}$ of RNA of different viruses; Lane 10, positive plasmids of CABYV, MABYV and SABYV; Lane 11, healthy control of cushaw leaf; Lane 12, no template.

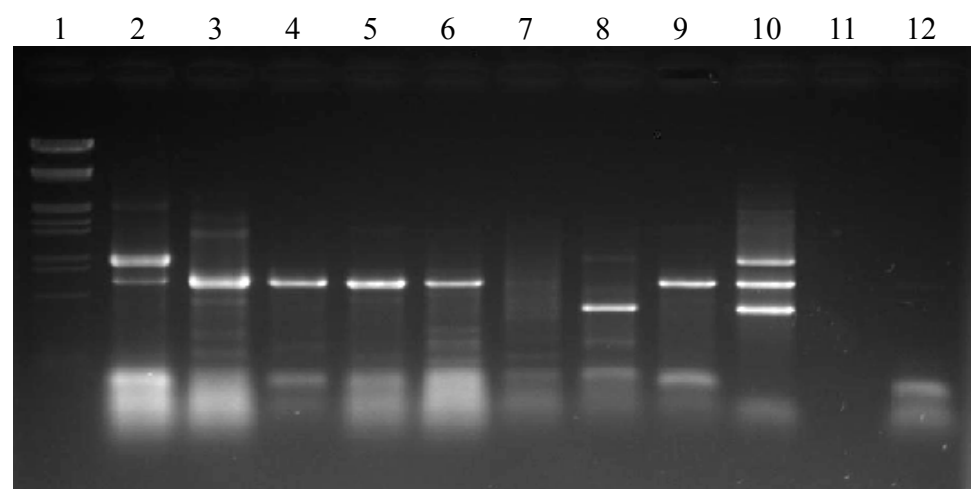

Figure 4. Agarose gel electrophoresis of multiplex RT-PCR products of different poleroviruses infecting cucurbits collected from different locations

Lane 1, DNA size marker, $\lambda$ DNA digested by EcoRI and HindIII; Lanes 2-4, cushaw 1, cushaw 2 and squash from Fujian Province, China; Lanes 5-6, cucumber 1, cucumber 2 from Beijing, China; Lanes 7-9, Suakwa vegetable sponge, squash and cushaw from Jiangxi Province, China; Lane 10, positive control of CABYV, MABYV and SABYV; Lane 11, no template; Lane 12, negative control of healthy cushaw leaf. 